Service social

\title{
La pauvreté chez les jeunes. Précarité économique et fragilité sociale, Madeleine Gauthier et Lucie Mercier, Québec, Institut québécois de recherche sur la culture, 1994, 190 pages.
}

\section{René Auclair}

Volume 44, numéro 3, 1995

Pauvreté

URI : https://id.erudit.org/iderudit/706711ar

DOI : https://doi.org/10.7202/706711ar

Aller au sommaire du numéro

Éditeur(s)

École de service social de l'Université Laval

ISSN

1708-1734 (numérique)

Découvrir la revue

Citer ce compte rendu

Auclair, R. (1995). Compte rendu de [La pauvreté chez les jeunes. Précarité économique et fragilité sociale, Madeleine Gauthier et Lucie Mercier, Québec, Institut québécois de recherche sur la culture, 1994, 190 pages.] Service social, 44(3), 165-166. https://doi.org/10.7202/706711ar d'utilisation que vous pouvez consulter en ligne.

https://apropos.erudit.org/fr/usagers/politique-dutilisation/ 


\section{RECENSIONS}

\section{LA PAUVRETÉ CHEZ LES JEUNES. PRÉCARITÉ ÉCONOMIQUE ET FRAGILITÉ SOCIALE}

Madeleine Gauthier et Lucie Mercier

Québec, Institut québécois de recherche sur la culture, 1994, 190 pages.

Comme I'annonce le feuillet publicitaire, l'ouvrage de Gauthier et Mercier part du fait que la pauvreté est un phénomène mouvant. II apparaît alors évident au fur et à mesure de l'analyse des travaux sur la question qu'il faut dépasser les moyennes statistiques pour s'attarder aux situations particulières. Selon les auteures le cas des jeunes est exemplaire en ce sens. Leur poids démographique peut faire en sorte que leurs caractéristiques disparaissent derrière les vues d'ensemble. L'examen des connaissances actuelles sur la question inspirera peut-être des solutions inédites ou des pistes nouvelles de recherche, la complexité des facteurs faisant appel à la pluralité des angles d'approche et à la concertation des différents agents.

Le premier chapitre est centré sur la pauvreté : définitions et solutions. Partant de la diversité des définitions et des façons $d^{\prime}$ identifier les pauvres, les auteures abordent tour à tour le rôle accru de l'État dans les solutions, la valorisation de l'initiative individuelle et le renouvellement des solidarités dans notre société.

Le deuxième chapitre aborde la difficile question des mesures de la pauvreté et le cas des jeunes. Les auteures y font référence à l'établissement des seuils de pauvreté, à la critique de ces derniers et aux taux actuels. Elles traitent par la suite la question des limites des mesures dans le cas des jeunes, celle des indices d'appauvrissement des jeunes et de la sélectivité de la pauvreté chez les jeunes. Leur conclusion s'intitule «Entre I'invisibilité et une visibilité qui effraie ", étant donné que la pauvreté chez les jeunes peut ne pas être très visible à cause du poids démographique du groupe des 15-24 ans. 
Les explications de la pauvreté font l'objet du troisième chapitre. Les différents facteurs identifiés sont d'une part le facteur marquant qu'est la situation de l'emploi et le facteur aggravant qui consiste en I'affaiblissement des liens sociaux. La relation complexe formation-emploi est centrale pour les auteures. Quant aux facteurs d'exclusion et aux stratégies de survie ou de dépendance, ils ont des conséquences multiples personnelles, collectives, économiques et sociales.

Les pistes de réflexion et d'action sont bien présentées par les auteures dans le quatrième chapitre: 1) la place du travail et la redécouverte du lien social, 2) le rôle intégrateur de l'État, 3) la solidarité entre générations, 4) la prévention, 5) le dépistage des périodes sensibles et 6) le repérage des dynamismes chez les jeunes.

Finalement, les auteures ont fait un résumé de ces pistes de réflexion à l'action à l'aide d'un tableau du style aide-mémoire qui à lui seul mérite qu'on s'y attarde.

Un ouvrage qui bouscule certains préjugés, mais qui surtout a le mérite d'organiser dans un modèle relativement simple un grand nombre de faits disparates et dispersés. Le non-spécialiste y trouvera donc son projet et découvrira un ensemble intégré et accessible de connaissances de base, alors que les plus avertis auront plaisir à pousser plus loin le questionnement et les débats de fond qu'il soulève. 